\title{
PROGRAM ZONASI DI SEKOLAH DASAR SEBAGAI UPAYA PEMERATAAN KUALITAS PENDIDIKAN DI INDONESIA
}

\author{
Azizah Arifinna Safarah ${ }^{1}$, Udik Budi Wibowo ${ }^{2}$ \\ 1,2Universitas Negeri Yogyakarta \\ 1,2Jl. Colombo No. 1, Karang Malang \\ Email: azizahfinna@gmail.com ${ }^{1}$, udik_budi@uny.ac.id ${ }^{2}$
}

\begin{abstract}
Abstrak:
Penelitian ini bertujuan untuk mengetahui upaya pemerataan kualitas pendidikan melalui program zonasi sekolah dasar. Penelitian ini merupakan studi literatur yang membahas program zonasi sekolah sebagai upaya pemerataan pendidikan. Peningkatan kualitas pendidikan tidak dapat dipisahkan dari pemerataan pendidikan. Pemerataan pendidikan memiliki dua elemen kunci yakni membekali individu dengan pengetahuan yang memungkinkan mereka mengambil bagian dalam segala aspek kehidupan serta memberikan akses pendidikan seluas-luasnya kepada setiap individu. Salah satu upaya dalam pemerataan pendidikan yang dilakukan oleh pemerintah yaitu program zonasi sekolah. Hasil studi menunjukkan bahwa program zonasi sekolah menjadi salah satu program yang efektif dari pemerintah dalam mewujudkan pemerataan pendidikan di Indonesia.
\end{abstract}

\begin{abstract}
:
This study aimed to determine the effort to equalize the quality of education through zoning program in the elementary school. This research was a literature study that discussed school zoning programs as an effort to distribute education. Improving the quality of education could not be separated from educational equity. Equitable education had two key elements, namely to equip individuals with knowledge that allowed them to take part in all aspects of life and provided access to education to the widest possible extent for each individual. One effort to equalize education carried out by the government was the school zoning program. The result of this study showed that the school zoning program was one of the government programs in realizing equitable education in Indonesia.
\end{abstract}

Kata kunci:

Program Zonasi, Pemerataan Pendidikan, Kualitas Pendidikan

PERMASALAHAN pendidikan yang menyangkut peningkatan kualitas pendidikan di Indonesia tidaklah sedikit. Banyak sekali kritik tentang kualitas pendidikan di Indonesia yang diluncurkan oleh akademisi maupun praktisi di bidang pendidikan. Salah satu permasalahan yang menjadi isu utama adalah belum terciptanya pemerataan pendidikan. Sistem pendidikan di Indonesia seharusnya memenuhi kebutuhan populasi yang besar, berkembang, beragam dan tersebar luas dan dengan perbedaan tingkat partisipasi antar wilayah.

Pemerintah Indonesia telah melakukan banyak hal untuk memperluas akses terhadap pendidikan bagi anak-anak di semua tahap pembelajaran. Kualitas pembelajaran yang dialami anak-anak selama tahun-tahun awal perkembangannya akan mempengaruhi kesiapan mereka dalam belajar saat mereka memasuki 
pendidikan dasar. Sistem pendidikan di masyarakat modern seharusnya memenuhi dua fungsi mutlak yaitu pertama membekali individu dengan pengetahuan yang memungkinkan mereka mengambil bagian dalam kehidupan sosial, ekonomi, dan politik. Kedua, memberikan akses pendidikan seluas-luasnya sebagai upaya pemerataan kualitas pendidikan (Coleman, 1968). Dua elemen kunci tersebut merupakan dasar munculnya pemerataan pendidikan guna meningkatkan kualitas pendidikan di Indonesia. Dengan demikian pemerataan pendidikan sangatlah penting dalam meningkatkan kualitas pendidikan. Upaya pemerintah untuk meningkatkan pemerataan pendidikan salah satunya yaitu melalui program zonasi sekolah. Program zonasi mulai diterapkan dari jenjang pendidikan paling rendah yaitu taman kanak-kanan (TK) hingga pendidikan menengah atas.

Berdasarkan uraian di atas, tulisan ini akan membahas tentang upaya pemerataan pendidikan melalui program zonasi di sekolah dasar beserta tantangan yang dihadapi dalam penerapan program zonasi di sekolah dasar.

\section{KAJIAN PUSTAKA}

\section{Pemerataan Pendidikan}

Reformasi pendidikan di Indonesia sudah dimulai sejak kemerdekaan. Berbagai komponen yang berhubungan dengan pendidikan diperbaiki dan ditingkatkan kualitasnya. Proses reformasi yang dialami Indonesia melalui berbagai hambatan atau kendala. Banyak pekerjaan rumah yang harus diselesaikan. Salah satu masalah yang harus diselesaikan yaitu masalah ketimpangan dalam penyediaan jasa pendidikan. Masih terdapat anak-anak yang tidak bersekolah. Indonesia masih belum mampu mewujudkan salah satu cita-citanya yaitu pendidikan untuk semua orang (education for all). Selain itu, juga masih terdapat masalah ekonomi yang mendasari anak dari kelompok yang tidak mampu atau miskin yang keluar dari sekolah ketika belum menyelesaikan jenjang pendidikannya. Hal-hal tersebut berhubungan dengan pemerataan atau ketimpangan kualitas dan penyedia jasa pendidikan yang ada di Indonesia. Konsep kesetaraan atau pemerataan menurut Coleman (1968) berarti beberapa hal, yaitu: memberikan pendidikan gratis sampai tingkat tertentu yang merupakan titik masuk utama bagi angkatan kerja; menyediakan kurikulum umum untuk semua anak, terlepas dari latar belakangnya; menyediakan sekolah yang sama bagi anak-anak dengan latar belakang bidang yang berbeda-beda; dan memberikan kesetaraan dalam kasih sayang, karena pajak daerah menyediakan sumber dukungan untuk sekolah. Konsep tersebut menjadi dasar program pemerataan atau kesetaraan dalam peningkatan kualitas pendidikan.

Sebagian besar diskusi tentang kesetaraan dalam pendidikan difokuskan pada bagaimana menyamakan akses dan partisipasi dalam berbagai tingkat pendidikan formal untuk berbagai kelompok sosial (Lynch \& Baker, 2005). Prioritas strategis untuk pendidikan ditetapkan dalam kerangka keseluruhan rencana nasional. Pendidikan merupakan prioritas kedua setelah reformasi sektor publik, dalam Rencana Pembangunan Jangka Menengah Nasional 2010-2014. Rencana Strategis 
MOEC untuk 2010-2014 memiliki lima misi yang menjadi dasar semua program pendidikan, yaitu: meningkatkan ketersediaan layanan pendidikan; meningkatkan keterjangkauan layanan pendidikan; meningkatkan kualitas dan relevansi layanan pendidikan; meningkatkan kesetaraan dalam memperoleh layanan pendidikan; dan meningkatkan kepastian/jaminan mendapatkan layanan pendidikan.

Strategi nasional dalam pengembangan anak-anak usia sekolah dasar menetapkan ambisi untuk memperluas perawatan dan pendidikan anak-anak sehingga menjangkau semua wilayah dan masyarakat dan dalam hal ini untuk meningkatkan kesetaraan dengan mencapai daerah terpencil, desa dan daerah perbatasan. Berdasarkan angka pemerintah, biaya untuk memperluas perawatan dan pendidikan anak usia sekolah dasar akan membutuhkan hampir dua kali lipat pengeluaran dari tahun 2010 sampai 2015 (OECD/Asian Development Bank, 2015)

Sejalan dengan komitmen pemerintah terhadap kesetaraan, upaya bersama diperlukan untuk lebih meningkatkan akses dan menawarkan kesempatan yang lebih banyak dan lebih baik kepada masyarakat dimana partisipasi dalam pendidikan dasar rendah. Indonesia perlu memulai dengan memperluas akses terhadap pendidikan anak usia dini dan meningkatkan kualitas melalui standar yang disahkan secara nasional, perizinan penyedia yang lebih kuat, dan pengembangan kader spesialis pengawas untuk tingkat pendidikan ini. Peningkatan partisipasi dalam pendidikan menengah atas sangat penting bagi Indonesia: saat ini kurang dari sepertiga orang Indonesia menyelesaikan pendidikan menengah. Peningkatan proporsi ini mengharuskan peningkatan relevansinya terhadap kehidupan, pekerjaan dan prospek belajar siswa lebih lanjut. Hal ini pada gilirannya berarti memberi perhatian lebih besar pada pengembangan keterampilan kognitif dan interpersonal. Ini juga diperlukan untuk memungkinkan fleksibilitas siswa masuk, keluar dan masuk kembali ke pendidikan tergantung pada keadaan keuangan dan sosial mereka, dan untuk menciptakan jalur antara akademis dan kejuruan. Meningkatnya skala dan keragaman permintaan siswa akan pendidikan dasar membutuhkan struktur penawaran yang lebih beragam. Sumber pendanaan juga perlu dilakukan diversifikasi dan insentif yang diciptakan untuk meningkatkan kualitas pendidikan. Perluasan dukungan beasiswa diperlukan untuk meningkatkan akses bagi siswa dari latar belakang yang lebih miskin.

Contoh kasus ketidakmeratanya pendidikan terjadi di Amerika Serikat. Ada ketidaksetaraan yang signifikan dalam kehidupan anak-anak Amerika, termasuk ketidaksetaraan dalam pendidikan yang diterima anak-anak ini. Ketidaksetaraan pendidikan ini tidak hanya mencakup perbedaan dalam pendanaan per murid tetapi juga dalam ukuran kelas, kualifikasi guru, dan sumber daya seperti buku, laboratorium, perpustakaan, komputer, dan kurikulum, serta kondisi fisik sekolah dan keselamatan siswa. Meskipun tidak semua sekolah yang didatangi anak-anak miskin adalah sekolah yang buruk, dan tidak semua sekolah yang didampingi oleh anak-anak yang berprestasi adalah sekolah yang baik, ada pola yang jelas. Anak-anak yang malang lebih cenderung menghadiri sekolah yang ramai dan kurang dilengkapi 
dengan guru yang kurang berkualitas daripada anak-anak dari keluarga yang lebih makmur. Mereka cenderung tidak memiliki komputer, buku, dan kursus akademis penempatan lanjutan. Untuk memberi satu contoh perbedaan sumber daya sekolah, distrik terkaya di New York menghabiskan lebih dari \$ 25.000 per murid pada saat bersamaan bahwa distrik paling miskin di Texas (Satz, 2007).

Negara berperforma tinggi seperti Amerika cenderung mendistribusikan sumber pendidikan sekolah secara lebih merata antara sekolah yang diuntungkan secara sosial ekonomi dan kurang beruntung. Di Indonesia, kepala sekolah yang berada di daerah pedesaan dan kurang beruntung melaporkan lebih banyak kekurangan atau sumber daya yang tidak memadai daripada kepala sekolah di kota dan daerah yang diuntungkan. Selain itu, kepala sekolah menengah bawah melaporkan lebih banyak kekurangan atau sumber daya yang tidak memadai daripada kepala sekolah menengah atas (OCDE, 2014)

Di tingkat provinsi, kemungkinan anak-anak yang mendaftar di pendidikan dasar dipengaruhi oleh konteks geografis (perkotaan/pedesaan) dan status sosial ekonomi rumah tangga. Anak-anak yang tinggal di daerah perkotaan lebih cenderung bersekolah di sekolah dasar. Angka partisipasi murni untuk sekolah dasar di perkotaan adalah 98,5\% sedangkan tingkat di daerah pedesaan adalah $96,8 \%$. Perbedaan geografis menjadi lebih luas di sekolah menengah pertama: 85,7\% anak sekolah menengah ke bawah bersekolah di perkotaan sedangkan hanya 74,4\% yang hadir di daerah pedesaan, memiliki kesenjangan lebih dari 10 persen (UNICEF, 2013).

Penelitian sebelumnya juga menjelaskan hubungan antara pilihan sekolah, jarak yang ditempuh ke sekolah, dan emisi gas yang terkait dengan transportasi. Sebanyak $20 \%$ transportasi mempengaruhi emisi gas rumah kaca secara global, dan $72 \%$-nya timbul dari transportasi berbasis jalan (Sims, Sudbery, Ilott, Heger, \& Ponting, 2014). Pilihan sekolah dan kebijakan zonasi sekolah memiliki implikasi bukan hanya untuk pendidikan tetapi juga untuk kesehatan masyarakat, transportasi, dan keberlanjutan. Oleh karena itu, upaya pemerataan pendidikan yang baik tidak hanya melihat dari segi kualitas output yang dihasilkan dari sekolah akan tetapi juga mempertimbangkan dampak kesehatan masyarakat, transportasi, dan keberlanjutan.

\section{Program Zonasi Sekolah Dasar}

Ada perbedaan pada Penerimaan Peserta Didik Baru (PPDB) tahun 2017 ini. Sesuai dengan Permendikbud Nomor 14 Tahun 2018 yang dikeluarkan Kementerian Pendidikan dan Kebudayaan tentang Penerimaan Peserta Didik Baru (PPDB) mulai dari Taman Kanak-kanak (TK) hingga jenjang SMA/SMK atau bentuk lain yang sederajat yang mengatur tentang program zonasi yang harus diterapkan sekolah dalam menerima calon peserta didik baru.

Permendikbud Nomor 17 Tahun 2017 Pasal 11 ayat 1 menyebutkan bahwa seleksi calon peserta didik baru kelas 1 (satu) SD dan yang sederajat mempertimbangkan kriteria dengan urutan prioritas sesuai dengan daya tampung berdasarkan ketentuan rombongan belajar salah satunya yaitu jarak tempat tinggal ke sekolah sesuai dengan ketentuan zonasi. Program zonasi ditetapkan bagi sekolah 
yang diselenggarakan oleh pemerintah daerah dengan ketentuan bahwa paling sedikit $90 \%$ dari total jumlah peserta didik yang diterima adalah calon peserta didik yang berdomisili pada radius zona terdekat dari sekolah. Penentuan zona disesuaikan dengan kondisi daerah tersebut berdasarkan jumlah ketersediaan daya tampung berdasarkan ketentuan rombongan belajar masing-masing sekolah dengan ketersediaan anak usia sekolah di daerah tersebut.

Pertanyaan selanjutnya yang muncul yaitu bagaimana dengan anak-anak di luar zona tetapi ingin bersekolah di sekolah kota yang notabene favorit. Berdasarkan Permendikbud nomor 14 tahun 2018 ada jalur prestasi bagi calon peserta didik yang berada di luar radius zona terdekat dari sekolah dengan persentasi paling banyak $5 \%$. Penerapan program zonasi memungkinkan setiap sekolah dapat berkembang dan meningkat dengan adanya heterogenitas siswa. Nantinya, semua sekolah haruslah menjadi sekolah favorit dan tidak ada lagi sekolah dengan kualitas yang rendah.

Program zonasi ini dirasa lebih memeratakan ketimpangan pendidikan antara perkotaan dan pedesaan. Anak-anak dari kalangan yang mampu dan pintar yang tinggal di daerah pedesaan cenderung memilih sekolah "favorit" di perkotaan. Label sekolah favorit di beberapa daerah menjadi momok yang menakutkan bagi sekolahsekolah yang ada di pedesaan yang sebenarnya memiliki akses yang sama dalam pendidikan. Selama ini, sistem cluster yang telah dijalankan di Indonesia membuat sekolah menjadi terkotak-kotakkan karena adanya kelompok atau cluster mulai dari sekolah yang berpredikat baik hingga rendah. Program zonasi inilah yang akhirnya menggantikan sistem cluster yang tujuannya memeratakan kualitas pendidikan baik di daerah kota maupun desa. Sekolah yang berlabel favorit tidak boleh lagi mengadakan tes pada proses penerimaan calon peserta didik baru, baik itu tes membaca, menulis, maupun berhitung. Hal tersebut sudah dilarang dan tercantum pada Permendikbud nomor 14 tahun 2018 bahwa seleksi calon peserta didik baru kelas satu sekolah dasar tidak dilakukan tes membaca, menulis, dan berhitung. Sekolah yang notabene menjadi impian para orang tua siswa untuk menyekolahkan anaknya di tempat yang populer dan favorit tidak dapat lagi menolak siswa yang dianggap memiliki kemampuan yang kurang. Sesungguhnya pembelajaran adalah menciptakan siswa yang belum berkemampuan menjadi dapat melakukan sesuatu atau mampu menyerap pembelajaran yang dilakukan di sekolah.

Suatu penelitian oleh Badan Perlindungan Lingkungan Amerika Serikat tahun 2003 menekankan pentingnya kedekatan sekolah dan pilihan sekolah dalam mendorong siswa untuk berjalan kaki dan bersepeda ke sekolah pada siswa sekolah dasar (Wilson, Marshall, Wilson, \& Krizek, 2010). Penelitian ini menunjukkan bahwa lebih banyak orang tua yang menyekolahkan anaknya di sekolah yang dekat dengan rumah dibandingkan dengan sekolah yang jaraknya jauh dari rumah sebagai alasan pilihan sekolah. Temuan ini berimplikasi signifikan bahwa kebijakan zonasi sekolah memberikan efek tidak hanya di pendidikan tertapi juga berimplikasi untuk mengatasi ketidakaktifan fisik dan kesehatan anak, peningkatan ketergantungan pada transportasi bermotor, kemacetan lalu lintas di sekitar sekolah, keamanan 
transportasi aktif ke sekolah, kualitas udara dan emisi gas rumah kaca. Penelitian lain yang dilakukan di Dunedin, Selandia Baru (Mandic et al., 2017) dengan tidak adanya zonasi sekolah menunjukkan bahwa ketergantungan terhadap transportasi bermotor lima kali lebih tinggi dibandingkan dengan yang berjalan kaki karena kedekatan sekolah. Hal tersebut menggambarkan bahwa siswa yang bersekolah di sekolah yang dekat dengan rumah dapat mendorong siswa untuk mandiri berangkat ke sekolah dengan berjalan kaki maupun bersepeda.

\section{Tantangan Penerapan Program Zonasi di Sekolah Dasar}

Indonesia telah membuat kemajuan yang baik dalam membangun fondasi yang diperlukan untuk meningkatkan kualitas pendidikan dasar. Kemajuan yang baik telah menciptakan guru yang berkualitas dan penyediaan ruang kelas dan bahan ajar di seluruh negeri, namun masih ada beberapa kesenjangan regional dan kabupaten baik dalam akses pelajar maupun sertifikasi guru di daerah terpencil dan miskin (OECD/Asian Development Bank, 2015). Meskipun ada kemajuan yang pesat dan kebanyakan siswa telah menerima pendidikan dasar, pemerataan akses dan penyedia layanan pendidikan, akan tetapi masih ada isu penting yang muncul. Masih ada variasi dalam kualitas pembelajaran yang diterima siswa di seluruh penjuru negeri dan hasilnya secara keseluruhan masih dikatakan rendah. Tantangannya adalah untuk terus berupaya meningkatkan kualitas secara terus-menerus di semua provinsi dan kabupaten sesuai dengan kerangka peningkatan kualitas yang ditetapkan dalam Standar Nasional Pendidikan di Indonesia.

Program zonasi memberikan kesempatan pada semua siswa untuk mendapatkan pendidikan di manapun tanpa dikotak-kotakkan. Setiap siswa mendapatkan porsinya di setiap daerah di mana ia tinggal. Tantangan selanjutnya adalah bagaimana sekolah dapat bersaing untuk meningkatkan kualitas sekolah dengan sumber daya manusia yang asli dari daerah tersebut. Sekolah harus dapat menciptakan pembelajaran yang kompetitif dan kondusif demi terciptanya iklim pembelajaran yang baik.

Berbagai keuntungan juga didapatkan oleh siswa dengan adanya program zonasi ini. Siswa lebih dekat dengan sekolah sehingga lebih mudah dikontrol oleh orang tua dan lebih menghemat biaya. Sekolah juga diuntungkan dengan program ini, karena peraturan minimal 20 siswa setiap kelas dapat terpenuhi. Siswa yang seharusnya sekolah di SD di daerah pedesaan haruslah bersekolah di sekolah di daerah sekitar rumah tinggalnya. Guru-guru yang bersertifikasi mendapatkan keuntungan karena jumlah siswa minimum dapat terpenuhi. Namun tantangannya adalah guru dan sekolah harus bekerja keras meningkatkan kualitas pembelajaran sehingga dapat menjadi sekolah favorit dan memiliki output yang lebih baik dan sesuai dengan tujuan pembelajaran. Lalu, bagaimana cara mengukur kualitas pendidikan di sekolah agar dapat dikatakan bahwa pendidikan di sekolah tersebut berkualitas?

Indikator pendidikan yang berkualitas berdasarkan Kementerian Pendidikan dan Kebudayaan (Kemdikbud, 2013) terdapat lima indikator yang benar-benar 
menggambarkan situasi pendidikan di Indonesia. Kelima indikator dikembangkan berdasarkan kebijakan pendidikan yang ditetapkan oleh Kementerian Pendidikan dan Kebudayaan. Indikator tersebut meliputi indikator ketersediaan layanan pendidikan, indikator keterjangkauan layanan pendidikan, indikator kualitas layanan pendidikan, indikator kesetaraan memperoleh layanan pendidikan, dan indikator kepastian memperoleh layanan pendidikan. Indikator tersebut yang seharusnya dijadikan tantangan bagi sekolah dan pemerintah untuk melayani pendidikan bagi masyarakat Indonesia.

Peran pemerintah dalam pemerataan pendidikan sangatlah dibutuhkan. Pemerintah kabupaten haruslah dapat memfasilitasi kebutuhan setiap sekolah yang berbeda-beda agar menjadi setara, terlebih bagi sekolah dengan mutu yang rendah. Program zonasi ini memungkinkan sekolah dapat memperoleh siswa dari yang pintar hingga siswa dengan kemampuan yang kurang. Hal tersebut akan membantu siswa dalam proses sharing atau berbagi ilmu antarsiswa. Iklim persaingan pun akan lebih terasa karena siswa harus mampu mengembangkan bakat dan kemampuannya agar dapat menjadi yang paling baik.

\section{SIMPULAN}

Program zonasi merupakan salah satu program pemerintah yang efektif dalam pemerataan kualitas pendidikan. Melalui program ini sekolah dapat bersaing untuk memiliki kualitas yang baik dan tidak kalah dengan sekolah yang sudah dianggap favorit. Program ini memberikan akses seluas-luasnya bagi sekolah dan siswa untuk mengembangkan kualitasnya. Siapapun siswa baik yang berkemampuan tinggi maupun rendah berhak bersekolah di sekolah yang tinggal di dekat tempat tinggalnya. Sekolah tidak diperkenankan menolak siswa dengan alasan belum bisa membaca, menulis, maupun berhitung, karena pembelajaran tersebut nantinya akan diajarkan pada tingkat pendidikan dasar. Sekolah juga tidak lagi diperbolehkan memindahkan siswa dengan kemampuan paling terbawah di kelasnya ke sekolah yang dikatakan lebih rendah kualitasnya. Karena sejatinya setiap siswa baik pintar maupun tidak berhak untuk memperoleh layanan pendidikan.

Program zonasi sekolah ternyata tidak hanya berimplikasi pada bidang pendidikan misalnya pemerataan pendidikan saja akan tetapi juga menyangkut dampak lingkungan seperti kemacetan lalu lintas, polusi udara, fisik dan kesehatan anak, serta ketergantungan pada transportasi bermotor. Adanya program zonasi sekolah mendorong siswa untuk mau berjalan kaki dan naik sepeda karena jaraknya yang dekat dengan tempat tinggal. 


\section{DAFTAR PUSTAKA}

Coleman, J. (1968). The Concept of Equality of Educational Opportunity. Harvard Educational Review, 38(1), 7-22. Retrieved from https:// files.eric.ed.gov/fulltext/ED015157.pdf

Kemdikbud. (2013). Indikator Pendidikan di Indonesia 2012/2013. Jakarta: Kemendikbud.

Lynch, K., \& Baker, J. (2005). Equality in Education: An Equality of Condition Perspective. Theory and Research in Education, 3(2), 131-164. Retrieved from https://journals.sagepub.com/doi/abs/10.1177/1477878505053298

Mandic, S., Sandretto, S., García Bengoechea, E., Hopkins, D., Moore, A., Rodda, J., \& Wilson, G. (2017). Enrolling in The Closest School or Not? Implications of School Choice Decisions for Active Transport to School. Journal of Transport and Health, 6, 347-357. Retrieved from https://www.sciencedirect.com/science/article/pii/S2214140517300695

OCDE. (2014). PISA 2012 Results: What Students Know and Can Do - Student Performance in Mathematics, Reading and Science (Volume I, Revised edition, February 2014). OCDE Publishing. https://doi.org/10.1787/9789264201118-en

OECD/Asian Development Bank. (2015). Education in Indonesia: Rising to The Challenge. Paris: OECD Publishing. https://doi.org/10.1525/as.1951.20.15.01p0699q

Satz, D. (2007). Equality, Adequacy, and Education for Citizenship. Ethics, 117(4), 623648. Retrieved from http://www.mit.edu/ shaslang/mprg/SatzEAEC.pdf

Sims, D., Sudbery, I., Ilott, N. E., Heger, A., \& Ponting, C. P. (2014). Sequencing Depth and Coverage: Key Considerations in Genomic Analyses. Nature Reviews Genetics, 15, 121-132. Retrieved from https://www.nature.com/articles/nrg3642

UNICEF (United Nations Children's Fund). (2013). Indonesia Socio Economic Survey 2011: Inequalities in Education. New York: UNICEF.

Wilson, E. J., Marshall, J., Wilson, R., \& Krizek, K. J. (2010). By Foot, Bus or Car: Children's School Travel and School Choice Policy. Environment and Planning A, 42(9), 2168-2185. https://doi.org/10.1068/a435 